\title{
Estimation of fracture aperture from petrophysical logs using teaching-learning-based optimization algorithm into a fuzzy inference system
}

\author{
Hesam Zarehparvar Ghoochaninejad ${ }^{1}\left(\right.$ D $\cdot$ Mohammad Reza Asef $^{\mathbf{1}} \cdot$ \\ Seyed Ali Moallemi ${ }^{2}$
}

Received: 19 April 2017 / Accepted: 25 September 2017/Published online: 4 October 2017

(c) The Author(s) 2017. This article is an open access publication

\begin{abstract}
Aperture, which refers to the opening size of a fracture, is a critical parameter controlling rock mass permeability. Moreover, distribution of permeability within the reservoir is commonly affected by natural fracture occurrences. In a water-based mud environment, boreholeimaging tools are able to identify both location and aperture size of the intersected fractures, whereas in oil-based environment, due to invasion of resistive mud into the fractures, this technique is impractical. Recently, some artificial intelligence techniques facilitated reliable estimations of reservoir parameters. In this paper, a teachinglearning-based optimization algorithm (TLBO) trained an initial fuzzy inference system to estimate hydraulic aperture of detected fractures using well logs responses. Comparing the results with real measurements revealed that the model can provide reliable estimations in both conductive and resistive mud environments, wherever the aperture size is unknown. TLBO, besides of its easier application, outperformed earlier optimization algorithms, which were used to evaluate the method effectiveness.
\end{abstract}

Keywords Aperture size · Fracture permeability · Fuzzy logic · Image logs · TLBO

Hesam Zarehparvar Ghoochaninejad

Hesam.ghoochaninejad@gmail.com

Faculty of Earth Sciences, Kharazmi University, Tehran, Iran

2 National Iranian Oil Company, Exploration Directorate, Tehran, Iran

\section{Introduction}

Natural fractures can affect essential reservoir characteristics tremendously. As a fluid conduit, natural open fractures can control the reservoir permeability (Boro et al. 2014). Conventional techniques of oil recovery may drain fractured reservoirs inefficiently, leading to early breakthrough in the secondary recovery (Alvarado and Manrique 2010; Speight 2016). In these cases, where production substantially takes place through fracture networks, aperture size is one of the basic parameters controlling reservoir permeability (Nelson 2001; Tiab and Donaldson 2015).

Mechanically, aperture is defined as the physical separation of the fracture walls (Fossen 2010). Moreover, the equivalent open part of the aperture is an indication of roughness characteristics, through which fluid can flow, and it is assumed as the hydraulic aperture as illustrated in Fig. 1 (Klimczak et al. 2010; Dardashti and Ajalloeian 2015).

Witherspoon et al. (1980) and Klimczak et al. (2010) indicated that the cubic law accurately describes the relationship between fluid flow and aperture size, considering fracture walls as smooth parallel plates. Accordingly, fracture permeability is related to the square of aperture size. Nevertheless, asperity and aperture size variation are commonly observed (Klimczak et al. 2010). Thus, the equivalent hydraulic aperture can express the relationship more accurately as follows (Sarkar et al. 2004; Watanabe et al. 2008; Ishibashi et al. 2012):

$k=\frac{w_{\mathrm{h}}^{2}}{12}$

where $K$ is the fracture permeability (millidarcy) and $w_{\mathrm{h}}$ is the hydraulic aperture size (microns). 
Fig. 1 A schematic illustration of fracture hydraulic and mechanical apertures with flow $(Q)$ passing through them

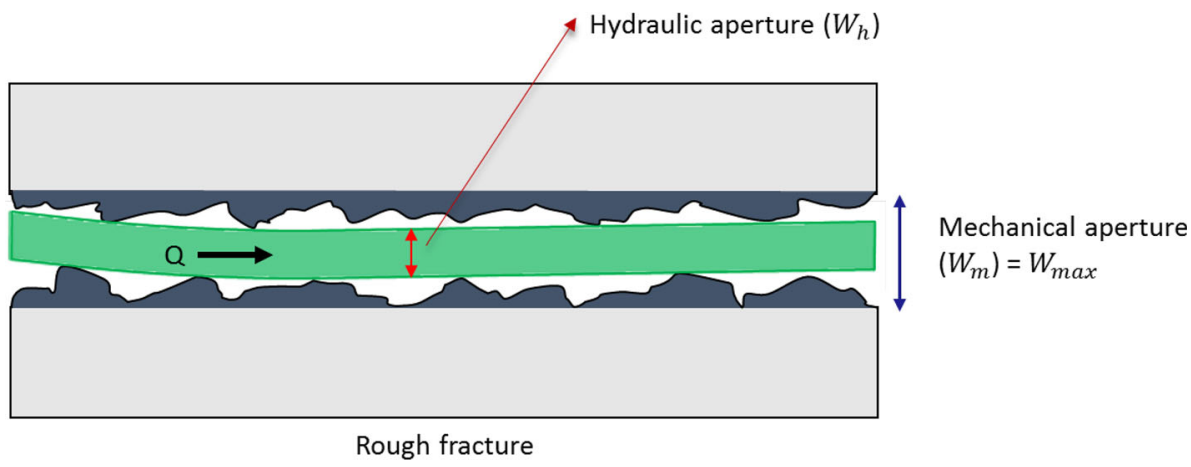

During fracture characterization, the aperture size is commonly characterized with the image logs. In conductive mud environments, imaging tools can determine fracture aperture on the order of microns (Tiab and Donaldson 2015), whereas in oil-based mud environments, due to the invasion of resistive mud into the fracture planes, the imaging tools such as Oil-Base Micro Imager (OBMI) display the same appearance for both the open and healed fractures (Bishop 2015). In addition, the vast majority of natural fractures have an aperture size less than the OBMI tool pixel width (Cheung et al. 2001). Statistics have shown that the most frequent range of aperture size is between 10 and 40 microns (Golf-Racht 1982). Therefore, the presence of a quick and cost-effective method to estimate aperture size of detected fractures can be useful, wherever the aperture size is unknown.

Nakashima and Kikuchi (2007) performed a quantitative estimation of fracture apertures, of a size higher than $0.2 \mathrm{~mm}$, using NMR logging data. They showed that there is a linear relationship between fracture aperture size and bulk-fluid porosity. $\mathrm{Wu}$ (2013) proposed a workflow to determine the relationship between aperture size and a fracture indicator value by using measurements from multiaxial electromagnetic induction well logging instruments. Ramandi et al. (2016) used X-ray micro-computed tomography to measure fracture apertures in a fractured coal sample from digital images. Shalaby and Islam (2017) have shown that fractured zones can be detected by using conventional well logs.

Recently, artificial intelligence techniques were utilized successfully for prediction of different reservoir parameters (Ahmadi 2011; Wang et al. 2013; Anifowose et al. 2017). El Ouahed et al. (2005) developed a 2-D fracture network map and fracture intensity map in Hassi Messaoud oil field by using fuzzy logic and artificial neural network. Ja'fari et al. (2012) suggested a model to estimate fracture intensity from conventional well logs by employing the adaptive neuro-fuzzy inference system. Accordingly, a fuzzy system maps input space to an output space using a set of fuzzy rules.
In this paper, a new method is introduced to estimate aperture size from well log data. The proposed method is an integration of fuzzy inference system and teachinglearning-based optimization algorithm (TLBO), in which the TLBO is utilized to train an initial fuzzy structure. TLBO is one of the most recent algorithms (Rao et al. 2011), which stands out as a powerful technique for optimization problems (Satapathy and Naik 2015; Kothavade and Deshpande 2016).

In order to evaluate the method effectiveness, various optimization algorithms available in the literature were employed to train the same fuzzy structure. Comparing the results indicated that the hybrid TLBO-Fuzzy Inference System (TLBOFIS) provides a higher level of accuracy. Finally, by estimating aperture size of detected fractures in both conductive and resistive mud environments, validation of the model was verified.

\section{Methodology}

\section{Fuzzy inference system}

Fuzzy set theory was first introduced by Zadeh (1965) as a method for handling data uncertainty. Unlike the Boolean logic, where variables take only a true or false value ( 1 or 0 ), fuzzy logic deals with the degree of truth and variables may have any value between 0 and 1 . Capability of fuzzy sets to express gradual transitions from membership to nonmembership provides a powerful representation of measurement uncertainties (Klir and Yuan 1995).

In fuzzy logic, the fuzzy inference system performs a formulation between the given input-output data, using a series of fuzzy if-then rules. As illustrated in Fig. 2, fuzzy inference system comprises five functional blocks: rule base, database (or dictionary), fuzzifier, inference engine, and defuzzifier. The rule base contains a selection of fuzzy rules, and the database defines their membership functions. Rule base and database together are usually known as the knowledge base (Jang 1993). By using membership functions in the fuzzifier block, the crisp (non-fuzzy) input data 
Fig. 2 Basic structure of fuzzy inference system

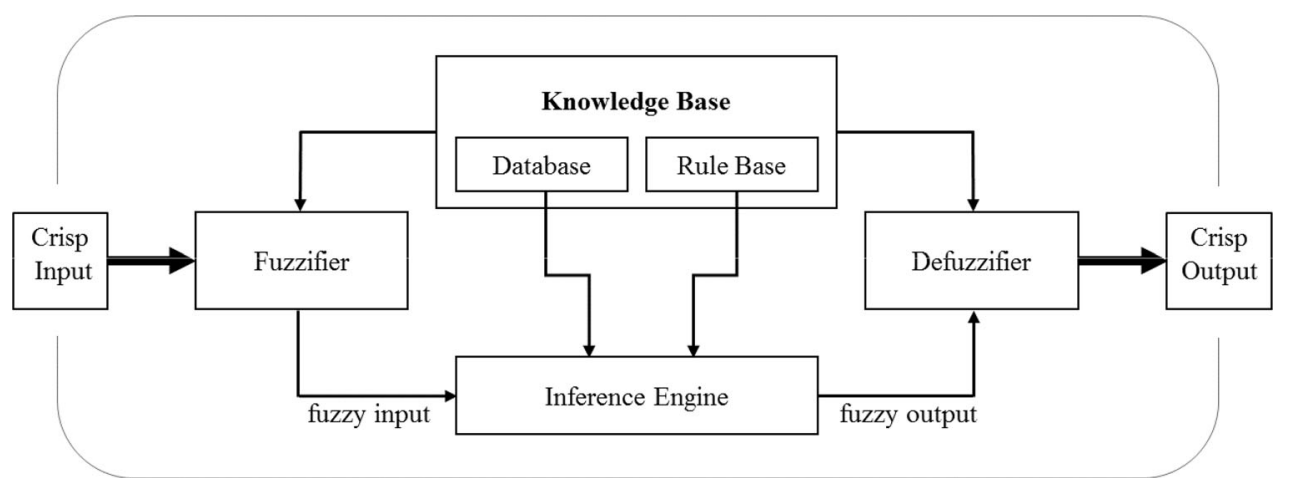

are transformed into the fuzzy sets; the fuzzy systems require a fuzzy input to be applied. The membership function defines how each point in the input space is mapped to a degree of membership between 0 and 1 (Matlab Users Guide 2013). Consequently, a set of if-then rules will be constructed, which relates the input and output datasets. The inference engine performs inference operation on the fuzzy rules. Finally, if a crisp output is required, defuzzifier transforms the fuzzy conclusions into the crisp values.

There are three types of fuzzy inference systems: Mamdani (Mamdani and Assilian 1975), Tsukamoto (Tsukamoto1979), and Takagi-Sugeno-Kang (Sugeno 1985). Sugeno system is a more compact and computationally efficient model, in which its output membership functions are either constant or linear (Matlab Users Guide 2013). Considering $\mathrm{x}$ and $\mathrm{y}$ as the input values and $\mathrm{z}$ as the crisp output, a typical rule in the Sugeno model has the form of:

\section{If $x$ is $\underline{\mathrm{A}}$ and $y$ is $B$, then $z=f(x, y)$}

where $A$ and $B$ are fuzzy sets and $f(x, y)$ is a function in consequent. Once the fuzzy structure initialized, the membership function parameters can be trained by employing optimization algorithms.

\section{Teaching-learning-based optimization algorithm (TLBO)}

TLBO is a metaheuristic algorithm, recently developed by Rao et al. (2011) as a method for constrained optimization problems. The TLBO inspired by the process of teaching and learning within a classroom works on the effect of influence of a teacher on learners and learners on each other. This algorithm comprises two parts: "teacher phase" and "learner phase." During the teacher phase, a teacher tries to increase the mean result of the class from the initial level to his own level (Rao 2015). The algorithm considers the most knowledgeable learner as the teacher. In this phase, existing solution updates according to the following expression:

$X_{j, k, i}^{\prime}=X_{j, k, i}+D_{j, k, i}$

where $X_{j, k, i}^{\prime}$ is the updated value of $X_{j, k, i}$ in subject $j$, learners $k$, and iteration $i . D_{j, k, i}$ is the difference between existing mean result and corresponding result of teacher in each subject.

Local search of the TLBO occurs during the learner phase. This phase uses accepted function values at the end of teacher phase as its own input. In this phase, learners enhance their knowledge by interacting randomly with themselves. A learner enhances knowledge of other learners, when he or she has more knowledge than they do.

The TLBO is a population-based evolutionary algorithm, which uses a population of solutions to proceed to the global solution (Ganesh and Reddy 2014). It is interesting to note that the TLBO does not require any algorithm-specific parameter. Common controlling parameters, such as the population size and number of iterations, are sufficient for its performance (Rao 2015). This ability of TLBO makes it an efficient tool, over the other algorithms, especially when dealing with multi-objective optimization problems (Zuperl and Cus 2016; Rai 2017).

\section{Hybrid TLBO-Fuzzy Inference System (TLBOFIS)}

Training of the initial fuzzy inference system may be assumed as an optimization problem to be solved using optimization techniques. Firstly, by applying subtractive clustering, an initial Sugeno fuzzy system is generated. Then, the TLBO is employed to train the initialized fuzzy model. Figure 3 illustrates the flowchart of the proposed hybrid TLBO-Fuzzy Inference System approach (TLBOFIS). The methodology may be divided into three stages: (1) data preparation; (2) initializing fuzzy inference system; and (3) optimizing the fuzzy system using TLBO. The following subsections explain each stage, respectively. 
Fig. 3 Flowchart of the proposed hybrid TLBOFIS approach

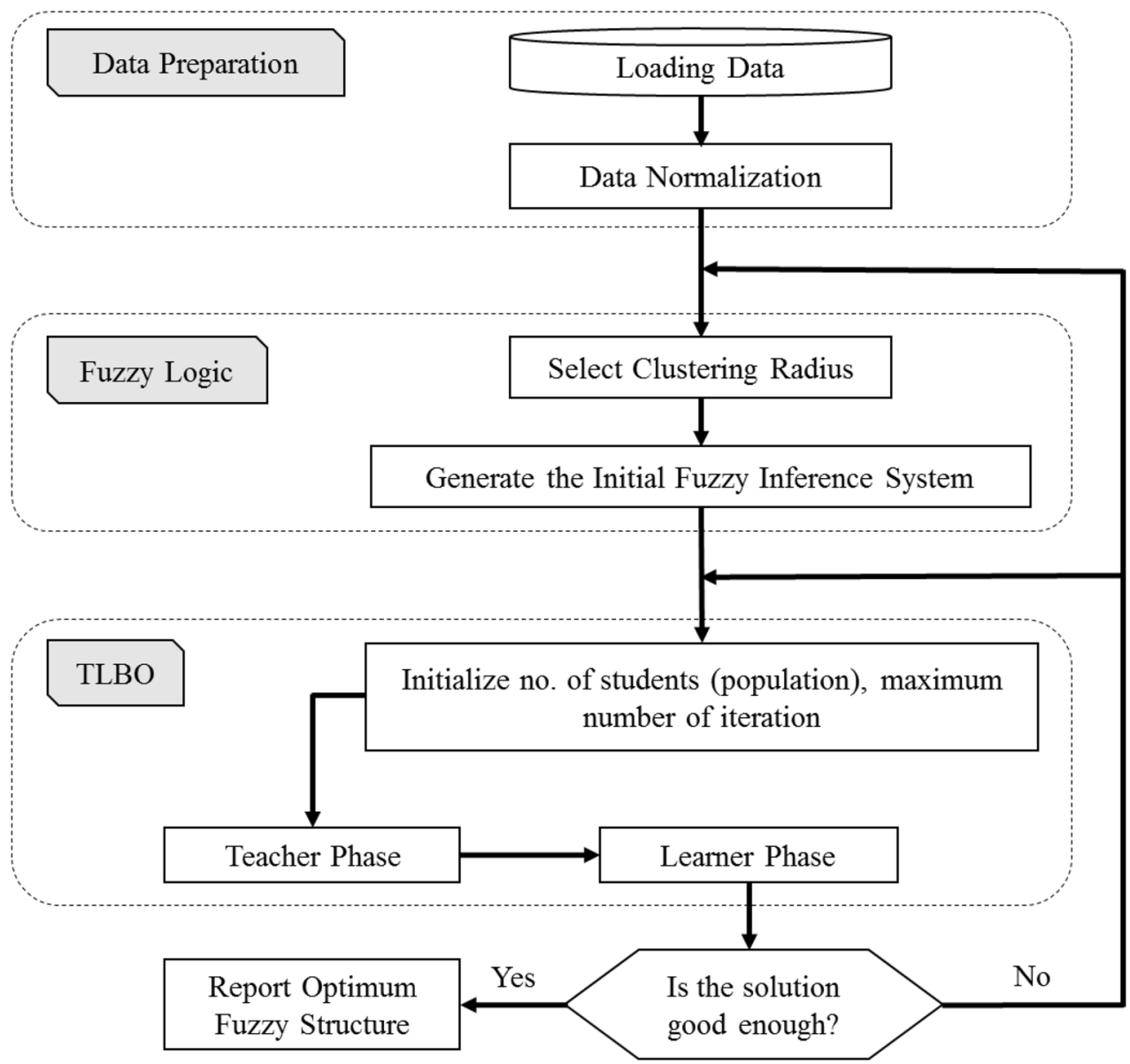

\section{Data preparation}

Here, Electrical Micro Imaging (EMI) logs along with the conventional well logs from the same intervals were the used data for initializing fuzzy model. These data were acquired from five wells drilled into two different hydrocarbon fields. The study area lies in the Zagros Basin in the Fars Province of Iran. The first field contains three wells with recorded well logs ranging in depths between 3050 and $3500 \mathrm{~m}$. In the second field, which includes the other two wells, studied depths range between 2500 and $2850 \mathrm{~m}$. Lithology of the logged intervals consists of anhydrite, bedded dolomite, limestone, and shale, assigned to the Permo-Triassic Dehram Group.

EMI is a water-based formation-imaging tool, which performs a qualitative micro-resistivity reading around the borehole. Six imaging pads of the EMI, in contrast to fourarm tools, provide more accurate hole volumes and diameter computations (Changxiong 2004).

Available image logs were processed using CIFLogGeoMatrix software, in order to obtain static and dynamic wellbore images. Using these images, several features such as the natural fractures, bed boundaries, and faults can be discriminated. Figure 4 displays EMI static and dynamic images in cross section of a studied well. Commonly, higher conductivities are illustrated by darker colors; therefore, the open fractures appear as dark-colored sinusoidal features, due to the mud conductivity (Fig. 4).

By processing available image logs, a total number of 132 conductive fractures were detected and their hydraulic aperture sizes were calculated. In the first studied hydrocarbon field, fractures show a NEE-SWW dominant strike, southeast azimuth, and dip inclination ranging between $75^{\circ}$ and $85^{\circ}$. Fracture orientations in the second hydrocarbon field are disordered. Nevertheless, NE-SW strike, mean azimuth of $110^{\circ}$ and mean dip of $78^{\circ}$, is dominant.

Luthi and Souhaité (1990) and Faivre (1993) showed that in a conductive mud environment, imaging tools measure the fracture aperture size as follows:

$W=c \cdot A \cdot R_{\mathrm{m}}^{b} \cdot R_{x o}^{1-b}$

where $W$ refers to fracture width (i.e., aperture); $R_{\mathrm{m}}$ and $R_{x o}$ indicate the resistivity of mud and shallow rock, respectively; $c$ is tool constant; and $b$ is a value slightly smaller than 1. Excess current $A$ is caused by the presence of fracture.

In the literature, various empirical models were proposed in order to relate the mechanical and hydraulic 
Fig. 4 A cross section of the studied wells, showing the EMI static and dynamic images. Additionally, a conductive fracture is specified

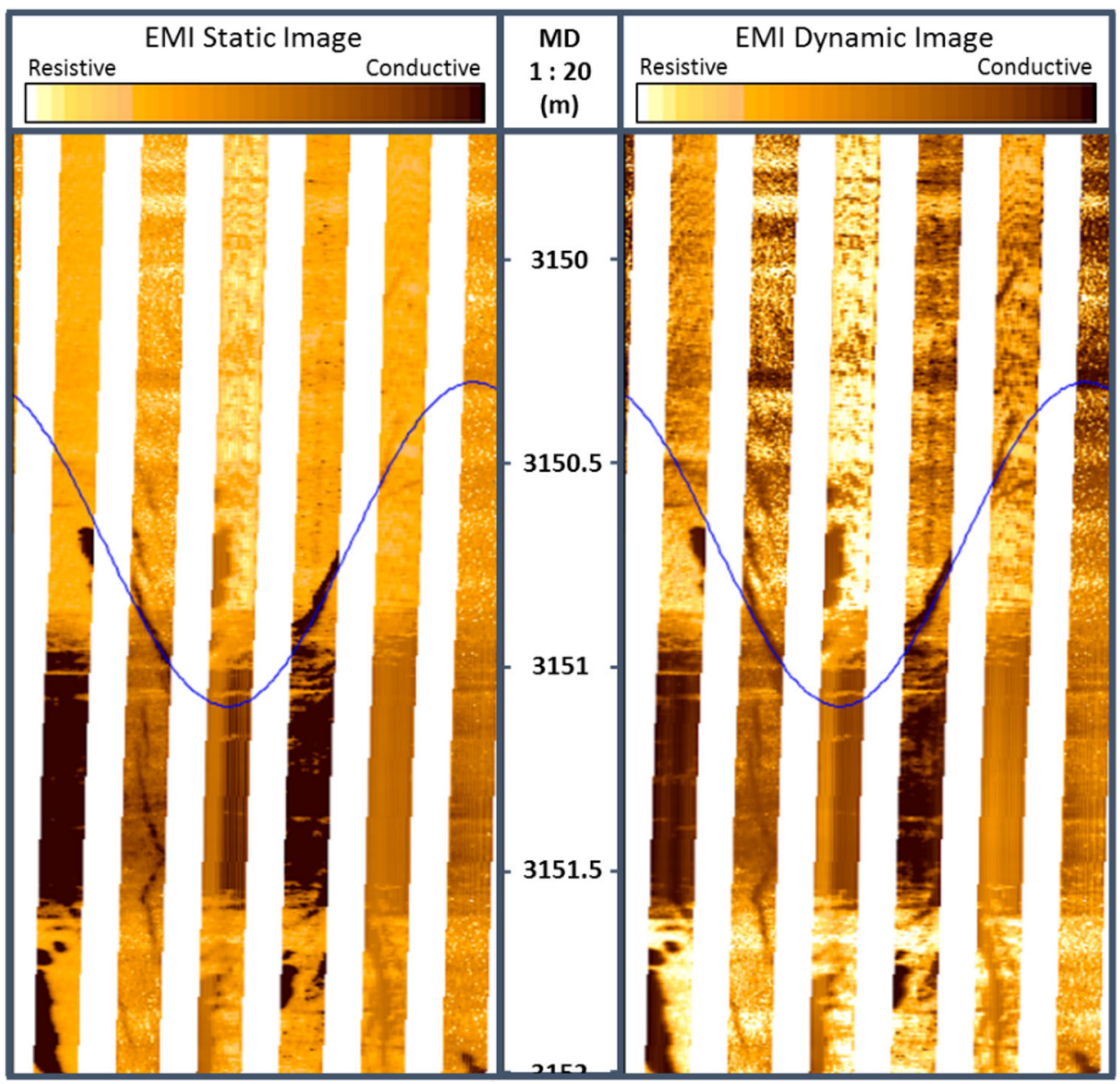

apertures (Renshaw 1995; Zimmerman and Bodvarsson 1996; Li and Jiang 2013). The CIFLog-GeoMatrix computes the average hydraulic aperture as the cubic mean value of fracture trace aperture.

In the next step, image logs were correlated against petrophysical well log and responses at the exact depth of each fracture were specified. In Fig. 5, measured aperture values are compared against acoustic travel time (DT), bulk density (RHOB), deep laterolog (LLD), gamma ray (GR), neutron porosity (NPHI), and photoelectric factor (PEF) logs. Among the available logs, LLD, NPHI, DT, and RHOB showed the highest correlations with aperture size and therefore, they were chosen as the input of the fuzzy model:

- LLD measures formation deep resistivity and, among other well $\operatorname{logs}$, has the highest correlation with aperture size. Generally, wider apertures show lower resistivities (Fig. 5).

- NPHI tracks hydrogen concentration in the formation and shows a linear relationship with measured aperture sizes, as illustrated in Fig. 5.

- DT displays travel time of elastic wave through the formation rock. Generally, void spaces reduce the speed of the sound (Serra 2008). Bigger apertures accompany with slower velocity records.

- RHOB is a record of formation bulk density and is related to the rock porosity. As seen in Fig. 5, lower densities imply bigger aperture sizes.

Final data sets, consisting of measured hydraulic aperture and well log responses, were merged and divided into two groups: a group including 98 sets for training the model and another group with 34 sets for testing.

In order to remove the effect value dimensions and achieve a better estimation, all input data were normalized between 0 and 1. Normalization was performed by the following expression:

$x_{i, \text { norm }}=\frac{x_{i}-\min \left(x_{i}\right)}{\max \left(x_{i}\right)-\min \left(x_{i}\right)}$

where $x_{i}$ is the data point to be normalized and $\min \left(x_{i}\right)$ and $\max \left(x_{i}\right)$ are the minimum and maximum values.

\section{Initializing fuzzy inference system}

In order to generate the initial fuzzy inference system and define membership functions, a fuzzy clustering technique

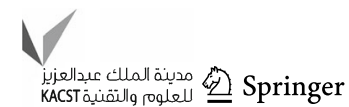



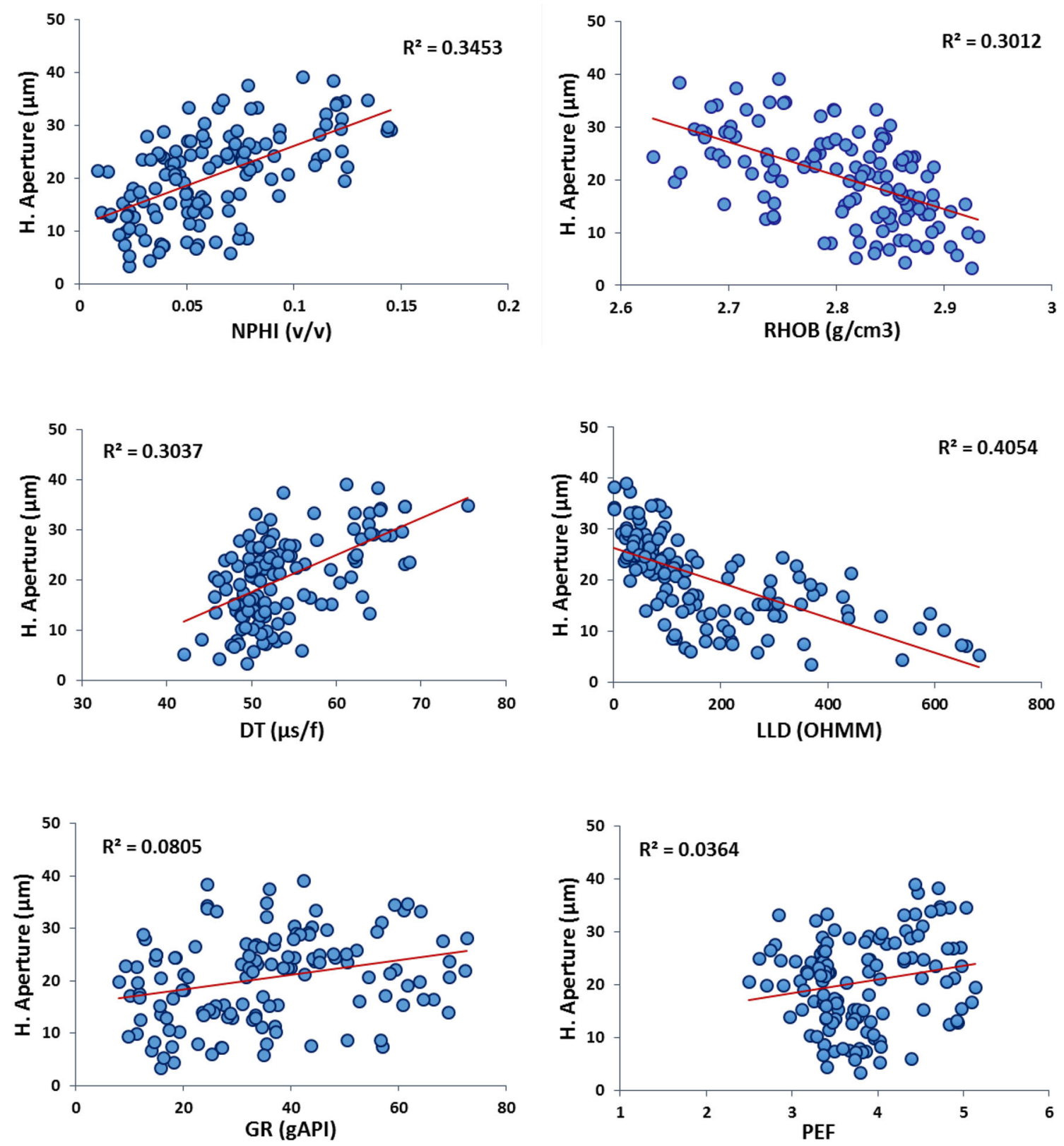

Fig. 5 Cross-plots of well logs responses versus the measured hydraulic aperture (H. Aperture) for detected fractures in the studied wells. $R^{2}$ indicates the coefficient of determination

may be used. Subtractive clustering and Fuzzy C-Means are two basic methods of fuzzy clustering. Here, a subtractive clustering method was employed to determine the fuzzy rules. In a set of data, subtractive clustering defines the number of clusters and cluster centers and returns a fuzzy structure that contains fuzzy if-then rules. This method eliminates the need of specifying grid resolution, in which the agreement between the accuracy and computational complexity must be regarded (Bataineh et al. 2011).

Membership functions define each crisp data with a degree of membership. The membership functions can have different forms, such as the triangular, trapezoidal, and Gaussian. Here, the Gaussian membership function shows the best fit to the input well logs (Fig. 6). Gaussian membership function is represented by center and width values:

$\mu_{A_{i}}(x)=\exp \left[-\frac{1}{2}\left(\frac{x-c_{i}}{\sigma_{i}}\right)^{2}\right]$

where $c_{i}$ and $\sigma_{i}$ are the mean (center) and standard deviation (width) of the $i$ th fuzzy set, respectively.

In subtractive clustering, cluster radius determines the range of influence of a cluster. The optimum clustering 

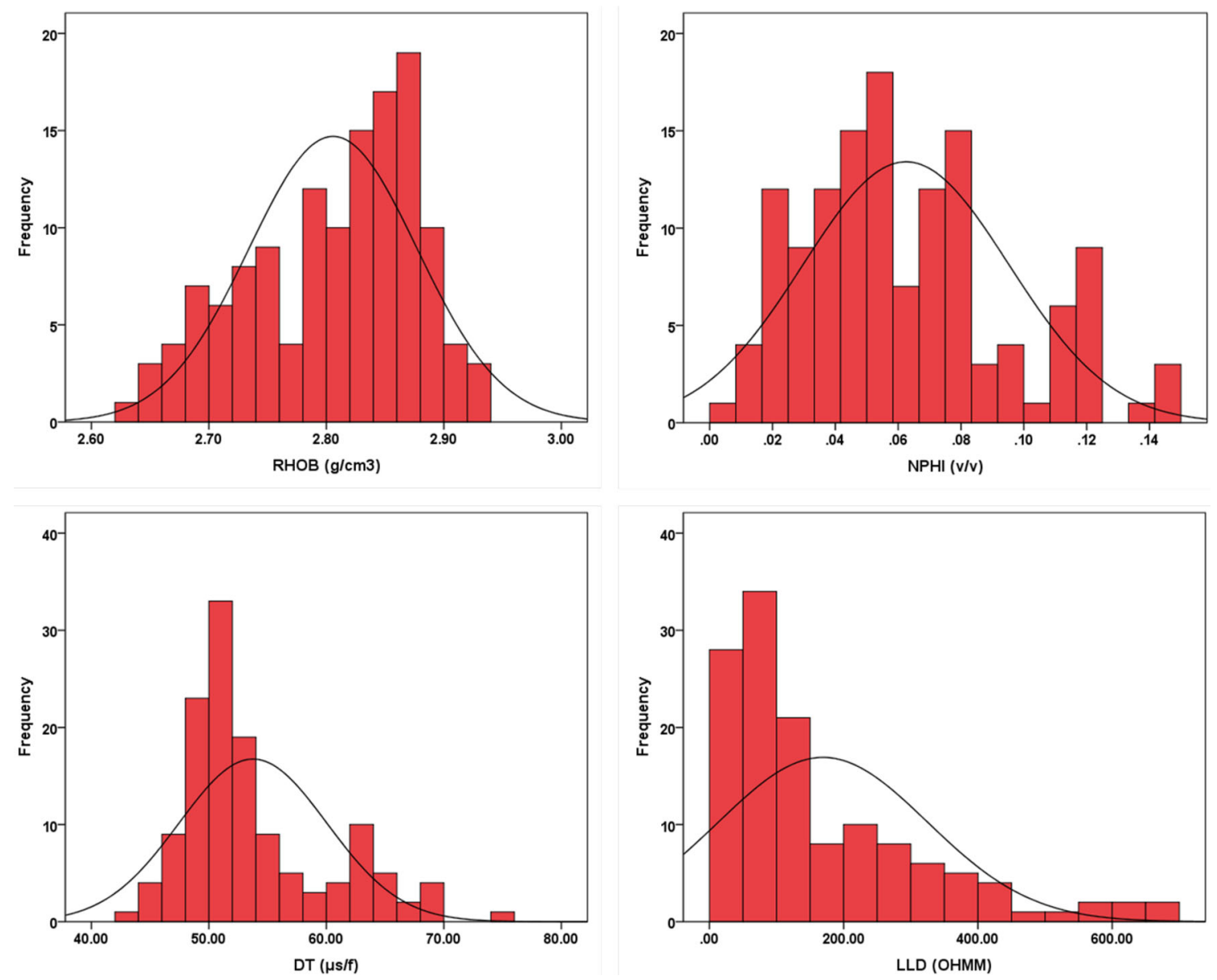

Fig. 6 Histograms showing the fitted Gaussian membership function to the RHOB, NPHI, DT, and LLD well logs

radius can be determined by trial and error. As discussed, the teaching-learning-based optimization algorithm is needless of any algorithm-specific parameter. However, common controlling parameters such as the population size and number of iterations can be modified in order to enhance the model accuracy. TLBO considers the number of learners as the population size (Rao 2015).

\section{Optimizing the fuzzy system using TLBO}

By training an initial fuzzy inference system, its membership function parameters are adjusted until the optimal solution is achieved. This tuning process can be performed utilizing various optimization algorithms. Sugeno fuzzy inference system trained with the neuro-adaptive learning was introduced by Jang (1993) as the adaptive neuro-fuzzy inference system (ANFIS). In this study, the optimization of initial Sugeno fuzzy system was performed using TLBO, rather than the classic neuro-adaptive method. The optimization process was repeated until a solution with desired satisfaction was achieved or the maximum number of iterations was reached. Figure 7 displays root-mean-square

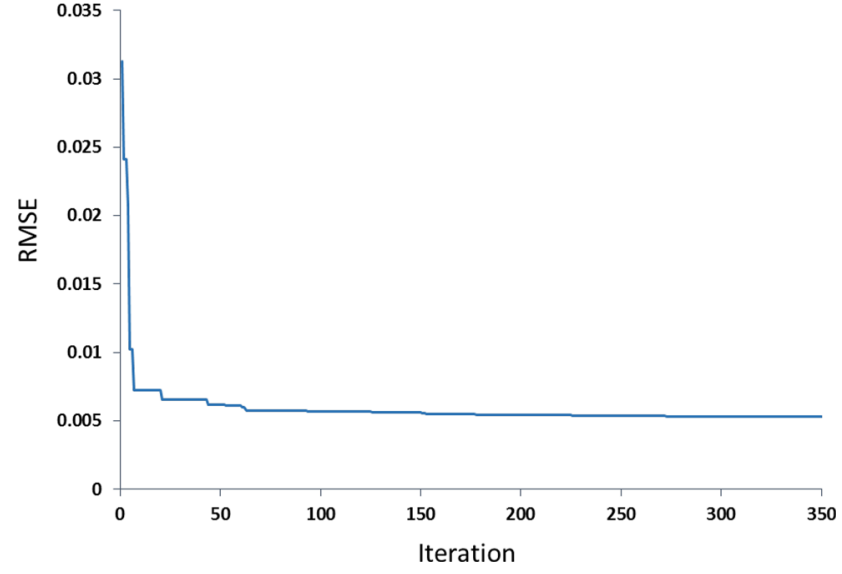

Fig. 7 Acquired RMSE by each iteration epoch of TLBOFIS (clustering radius $=0.6$ ) in training data

errors (RMSE) obtained by each iteration of hybrid TLBOFIS. Accordingly, RMSE declined mostly in the early iterations. 
Table 1 Correlation coefficients $(R)$, RMSE, and number of fuzzy rules achieved by each clustering radius

\begin{tabular}{llll}
\hline Clustering radius & Fuzzy rules & RMSE & $R$ \\
\hline 0.1 & 92 & 0.0056 & 0.7999 \\
0.2 & 65 & 0.0052 & 0.8041 \\
0.3 & 39 & 0.0049 & 0.8357 \\
0.4 & 11 & 0.0050 & 0.8200 \\
0.5 & 7 & 0.0044 & 0.8668 \\
$\mathbf{0 . 6}$ & $\mathbf{6}$ & $\mathbf{0 . 0 0 4 4}$ & $\mathbf{0 . 8 7 3 5}$ \\
0.7 & 4 & 0.0050 & 0.8546 \\
0.8 & 2 & 0.0045 & 0.8665 \\
0.9 & 2 & 0.0048 & 0.8581 \\
1 & 2 & 0.0055 & 0.7816 \\
\hline
\end{tabular}

The optimum radius and corresponding parameters are bolded

\section{Results and discussion}

By applying subtractive clustering, a Sugeno fuzzy inference system was initialized. The cluster radius was varied gradually from 0.1 to 1 by intervals of 0.1 , in order to find the optimal radius. As given in Table 1, clustering with a radius of 0.6 provides the hybrid TLBOFIS with the highest accuracy. For evaluating the method, several optimization algorithms were employed to train the fuzzy structure using the same database. These algorithms contain Neuro-Fuzzy (ANFIS), Genetic Algorithm (GA), Artificial Bee Colony (ABC), and Ant Colony Optimization (ACO). For all these algorithms, including TLBO, the population size and maximum number of iterations were considered as 800 and 350, respectively. Associated

Table 2 Algorithm-specific parameters and the highest accuracy achieved by each method, in test data

\begin{tabular}{|c|c|c|c|}
\hline Used method & RMSE & $\mathrm{R}$ & Algorithm-specific parameters \\
\hline ABC-FIS & 0.0055 & 0.7902 & $\begin{array}{l}\text { Number of onlooker bees }=800 \\
\text { Trial limit }(L)=600 \\
\text { Acceleration coefficient upper bound }(a)=1\end{array}$ \\
\hline ACOFIS & 0.0059 & 0.0804 & $\begin{array}{l}\text { Sample size }=400 \\
\text { Intensification factor }(q)=0.5 \\
\text { Deviation-distance ratio (zeta) }=1\end{array}$ \\
\hline ANFIS & 0.0061 & 0.7556 & Optimization method $=$ hybrid \\
\hline GA-FIS & 0.0048 & 0.8414 & $\begin{array}{l}\text { Crossover percentage }(\mathrm{pc})=0.5 \\
\text { Number of parents }(\mathrm{nc})=400 \\
\text { Mutation percentage }(\mathrm{pm})=0.6 \\
\text { Number of mutants }(\mathrm{nm})=480 \\
\text { Mutation rate }(\mathrm{mu})=0.25 \\
\text { Selection pressure (beta) }=6 \\
\text { Gamma }=0.8\end{array}$ \\
\hline TLBOFIS & 0.0044 & 0.8735 & Needless \\
\hline
\end{tabular}

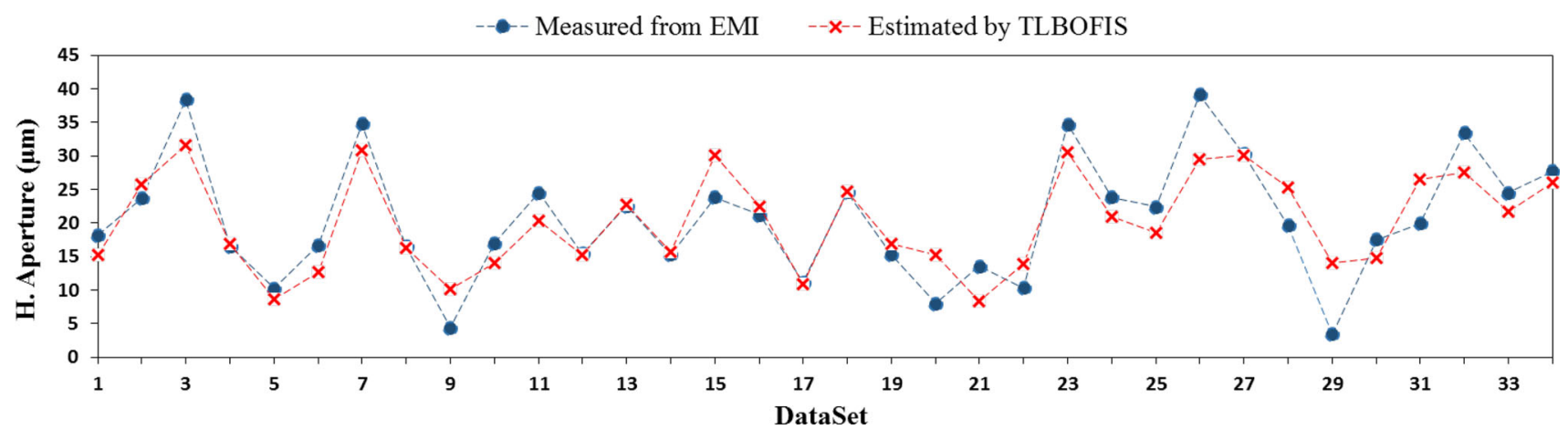

Fig. 8 A comparison between the measured hydraulic aperture and TLBOFIS predicted values for fractures in the test datasets 

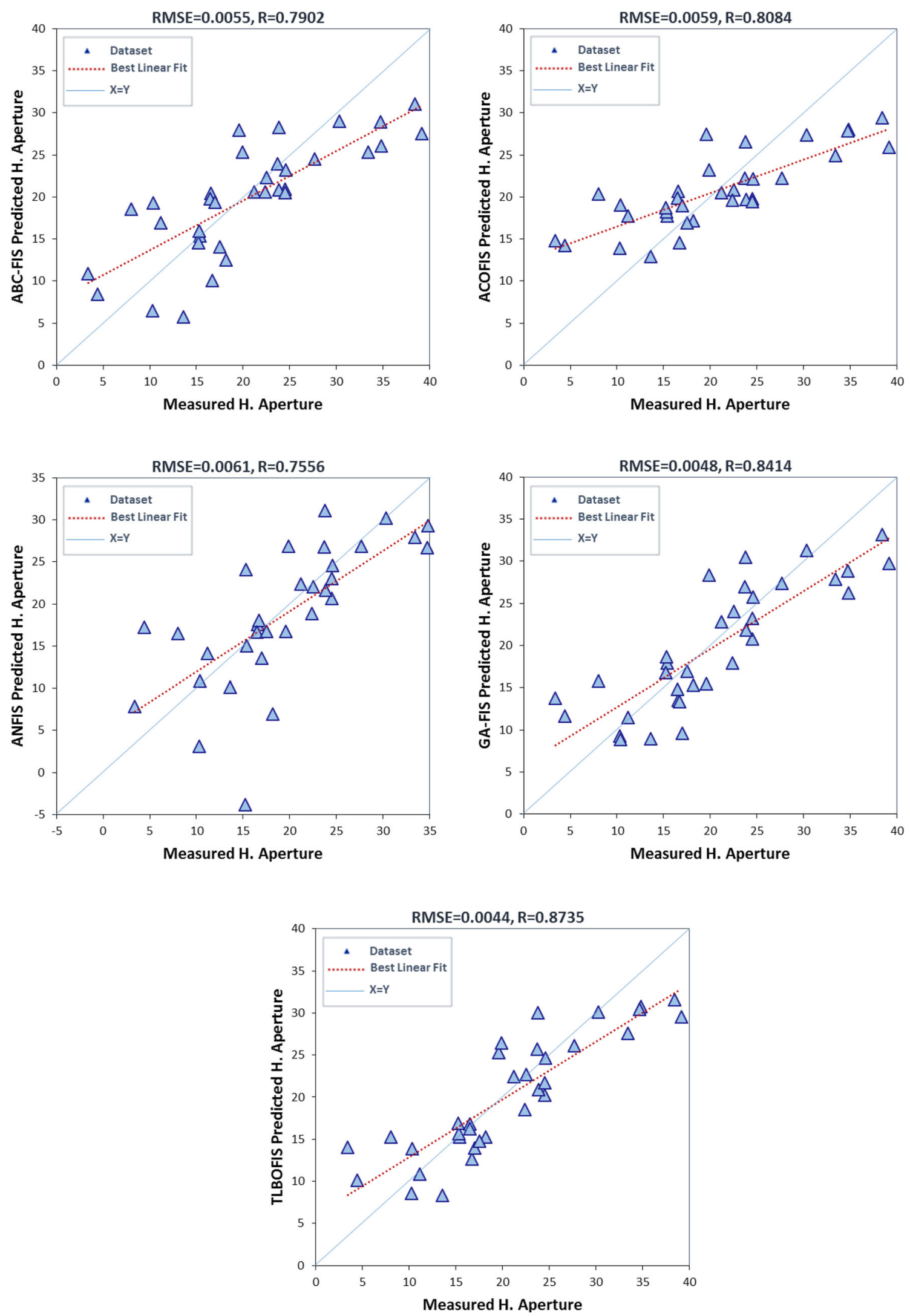

Fig. 9 Cross-plots showing correlation between the measured and estimated values of aperture size, for each methods 


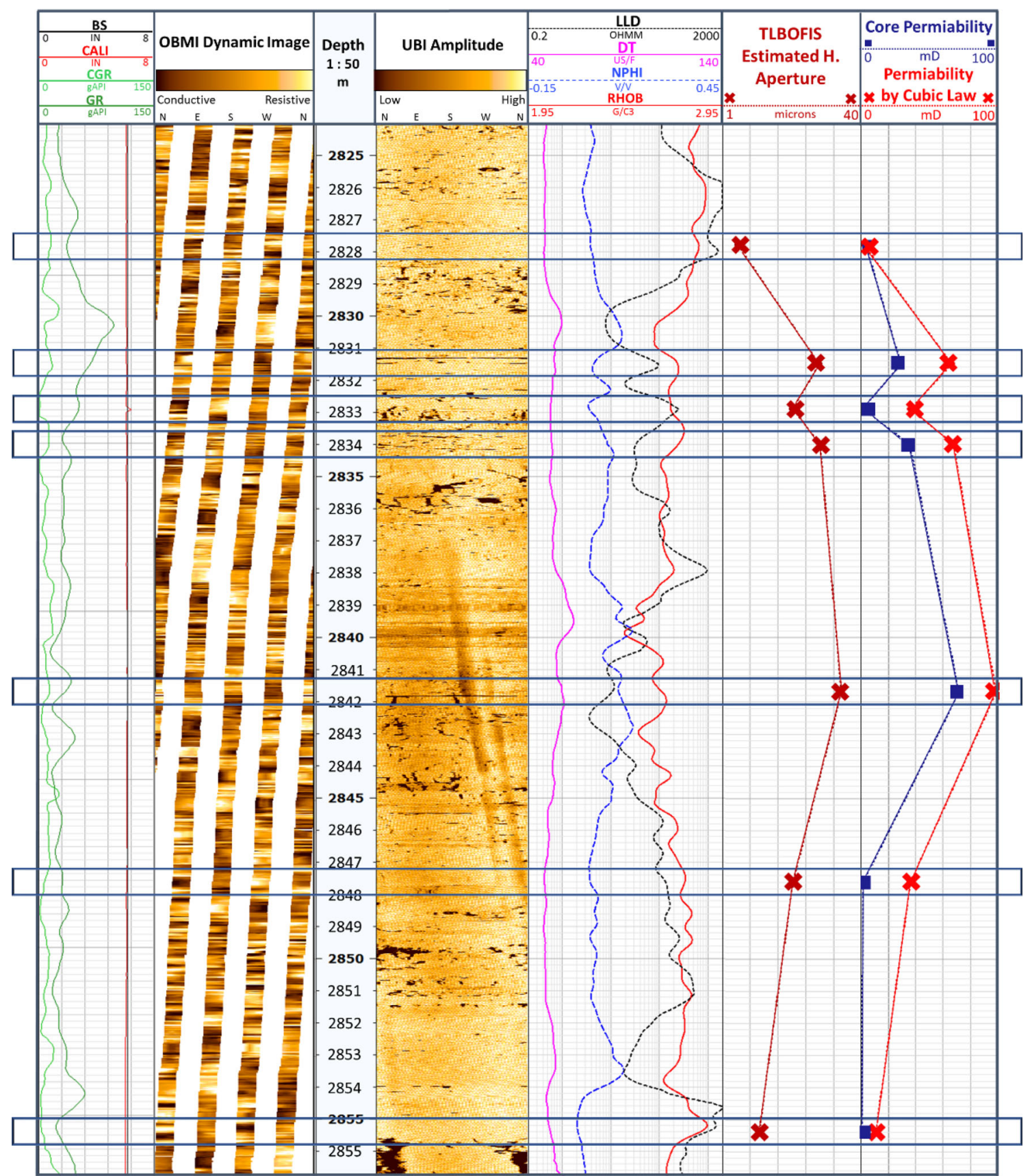

Fig. 10 Processed image logs, conventional well logs, and estimated hydraulic aperture for each fracture plane. The last column shows the comparison between core permeability and derived values

algorithm-specific parameters and the highest accuracy of each method are presented in Table 2.

Estimated hydraulic aperture (by TLBOFIS method) and measured values (from EMI log) are compared in Fig. 8. Integration of the fuzzy inference system with TLBO resulted in a correlation coefficient of 0.8735 and RMSE equal to 0.0044 that significantly improved compared to the other methods. Cross-plots of all methods are illustrated in Fig. 9.
In the next step, a new wellbore from a different hydrocarbon field (the third field) was selected to evaluate the model performance in an oil-based environment. The field was located in Fars Province in southern territories of Iran. Mud system used for drilling was oil based, with an oil-water ratio of 70/30. The studied well contained both the OBMI and UBI image logs and a full set of conventional well logs. The RCAL and SCAL core test data, also, were available for recovered cores from a 50-m interval. 
The cored interval lies in the Upper Dalan Formation (of Upper Permian age) with a lithology consisting of carbonate and anhydrite.

By processing available image logs on the cored interval, a total number of seven intersected fractures were detected. Afterward, well log records (RHOB, NPHI, DT, and LLD) at the exact depth of each fracture were specified. By normalization of input data, the developed TLBOFIS model was applied and the hydraulic aperture size of intersected fractures was estimated. The core permeability to the air (from SCAL data) was employed in order to relate estimated values to real measurements. Using Eq. (1), the estimated hydraulic aperture was converted to permeability values. Figure 10 illustrates the processed image logs and petrophysical well logs in the studied interval. The estimated hydraulic aperture and permeability for each fracture plane are also presented. Comparing the measured permeability (from core test data) and estimated permeability (from cubic law) showed a coefficient of determination $\left(R^{2}\right)$ equal to 0.82 that indicates a strong relationship.

\section{Conclusion}

Aperture size is a key parameter to indicate the influence of natural fractures on reservoir performance, and borehole imaging is the basic method for its measurement. In oilbased mud environment, however, image logs are unable to specify this parameter. In this paper, a novel method was introduced to estimate hydraulic aperture of detected fractures using conventional well logs. Required well logs are usually available in most of the drilled wells. The proposed method utilized the TLBO algorithm, in order to optimize an initial Sugeno fuzzy inference system. The TLBO does not need of any algorithm-specific parameter, and this feature makes it a useful tool for optimization problems. Examination of the developed model, in both conductive and resistive mud environments, confirmed that the estimated values are in a good agreement with real measurements. The proposed hybrid method, as an easygoing tool, may also be employed to estimate other reservoir parameters.

Acknowledgements The authors would like to appreciate Dr. Ali Kadkhodaie-Ilkhchi and Christian Klimczak for helping during the research.

Open Access This article is distributed under the terms of the Creative Commons Attribution 4.0 International License (http:// creativecommons.org/licenses/by/4.0/), which permits unrestricted use, distribution, and reproduction in any medium, provided you give appropriate credit to the original author(s) and the source, provide a link to the Creative Commons license, and indicate if changes were made.

\section{References}

Ahmadi MA (2011) Prediction of asphaltene precipitation using artificial neural network optimized by imperialist competitive algorithm. J Petrol Explor Prod Technol 1(2):99-106

Alvarado M, Manrique E (2010) Enhanced oil recovery: an update review. Energies 3:1529-1575

Anifowose FA, Labadin J, Abdulraheem A (2017) Hybrid intelligent systems in petroleum reservoir characterization and modeling: the journey so far and the challenges ahead. J Petrol Explor Prod Technol 7(1):251-263. doi:10.1007/s13202-016-0257-3

Bataineh KM, Najia M, Saqera M (2011) A comparison study between various fuzzy clustering algorithms. Jordan J Mech Ind Eng 5(4):335-343

Bishop K (2015) Mechanical stratigraphy of the Vaca Muerta Formation, Neuquen Basin, Argentina. M.Sc. Thesis, Colorado School of Mines, USA

Boro H, Rosero E, Bertotti G (2014) Fracture-network analysis of the Latemar Platform (northern Italy): integrating outcrop studies to constrain the hydraulic properties of fractures in reservoir models. Pet Geosci 20:79-92

Changxiong W (2004) EMI log evaluation report (Internal report). Geoscience Center, Ahwaz, Iran

Cheung P, Hayman A, Laronga R, Cook G, Flournoy G, Goetz Marshal M, Hansen S, Lamb M, Li B, Larsen M, Orgren M, Redden J (2001) A clear picture in oil-base muds. Oilfield Rev 13(4):2-27

Dardashti AF, Ajalloeian R (2015) Evaluation of hydraulic aperture of the joints of Behesht Abad Dam foundation, Iran. Open J Geol 5:375-382

El Ouahed AK, Tiab D, Mazouzi A (2005) Application of artificial intelligence to characterize naturally fractured zones in Hassi Messaoud Oil Field, Algeria. J Petrol Sci Eng 49(3):122-141

Faivre O (1993) Fracture evaluation from quantitative azimuthal resistivity. In: Society of Petroleum Engineering, 68th annual technical conference and exhibition, Houston, Texas, pp 179-192

Fossen H (2010) Structural geology. Cambridge University Press, Cambridge

Ganesh BS, Reddy AS (2014) Teaching learning based optimization for economic dispatch problem with valve point loading effect. Int J Educ Appl Res 4(1):9-15

Golf-Racht TD (1982) Fundamentals of Fractured Reservoir Engineering. Development in Petroleum Science, no 12, Elsevier Scientific Pub Co, Amsterdam

Ishibashi T, Watanabe N, Hirano N, Okamoto A, Tsuchiya N (2012) Experimental and numerical evaluation of channeling flow in fractured type of geothermal reservoir. In: Proceedings of 37th workshop on geothermal reservoir engineering, Stanford University, Stanford, California, pp 759-766

Ja'fari A, Kadkhodaie-Ilkhchi A, Sharghi Y, Ghanavati K (2012) Fracture density estimation from petrophysical log data using the adaptive neuro-fuzzy inference system. J Geophys Eng 9:105-114. doi:10.1088/1742-2132/9/1/013

Jang JSR (1993) ANFIS: adaptive-network-based fuzzy inference system. IEEE Trans Syst Man Cybern 23(3):665-685

Klimczak C, Schultz RA, Parashar R, Reeves DM (2010) Cubic law with aperture-length correlation: implications for network scale fluid flow. Hydrogeol J 18:851-862

Klir GJ, Yuan B (1995) Fuzzy sets and fuzzy logic: theory and applications. Prentice Hall, Englewood Cliffs

Kothavade SV, Deshpande SP (2016) Teaching learning based optimization algorithm to solve assembly line balancing problem. Int J Curr Eng Technol 6(5):1558-1561 
Li B, Jiang Y (2013) Quantitative estimation of fluid flow mechanism in rock fracture taking into account the influences of JRC and Reynolds number. J MMIJ 129:479-484 (in Japanese)

Luthi SM, Souhaité P (1990) Fracture apertures from electrical borehole scans. J Geophys 55(7):821-833

Mamdani EH, Assilian S (1975) An experimental in linguistic synthesis with a fuzzy logic control. Int J Man Mach Stud 7:1-13

Matlab User's Guide (2013) Fuzzy logic toolbox. Matlab CD-ROM. The Mathworks, Inc

Nakashima Y, Kikuchi T (2007) Estimation of the apertures of watersaturated fractures by nuclear magnetic resonance well logging. Geophys Prospect 55(2):235-254

Nelson RA (2001) Geologic analysis of naturally fractured reservoirs, 2nd edn. Butterworth-Heinemann, Gulf Professional Publishing, Oxford, p 332

Rai DP (2017) Comments on "A note on multi-objective improved teaching-learning based optimization algorithm (MO-ITLBO)". Int J Ind Eng Comput 8(2):179-190. doi:10.5267/j.ijiec.2016.11. 002

Ramandi HL, Armstrong RT, Mostaghimi P (2016) Micro-CT image calibration to improve fracture aperture measurement. Case Stud Nondestruct Test Eval. doi:10.1016/j.csndt.2016.03.001 (in press)

Rao RV (2015) Review of applications of TLBO algorithm and a tutorial for beginners to solve the unconstrained and constrained optimization problems. Decis Sci Lett 5:1-30

Rao RV, Savsani VJ, Vakharia DP (2011) Teaching-learning-based optimization: a novel method for constrained mechanical design optimization problems. Comput-Aided Des 43(3):303-315

Renshaw CE (1995) On the relationship between mechanical and hydraulic apertures in rough-walled fractures. J Geophys Res 100:24629-24636

Sarkar S, Toksoz MN, Burns D (2004) Fluid flow modeling in fractures. Massachusetts Institute of Technology, Earth, Atmospheric and Planetary Sciences, Cambridge

Satapathy SC, Naik A (2015) A modified teaching-learning-based optimization (mTLBO) for global search. Recent Pat Comput Sci $6(1): 60-72$

Serra O (2008) Well logging handbook. Editions Technip, Paris

Shalaby MR, Islam MA (2017) Fracture detection using conventional well logging in carbonate Matulla Formation, Geisum oil field,
Southern Gulf of Suez, Egypt. J Petrol Explor Prod Technol. doi:10.1007/s13202-017-0343-1

Speight JG (2016) Introduction to enhanced recovery methods for heavy oil and tar sands, 2nd edn. Gulf Professional Publishing, Elsevier, Oxford

Sugeno M (1985) Industrial applications of fuzzy control. Elsevier Science Publisher, North Holland

Tiab D, Donaldson EC (2015) Petrophysics: theory and practice of measuring reservoir rock and fluid transport properties, 4th edn. Gulf Professional Publishing, Elsevier, Oxford

Tsukamoto Y (1979) An approach to fuzzy reasoning method. In: Gupta MM, Ragade RK, Yager RR (eds) Advances in fuzzy sets theory and applications. North-Holland, Amsterdam, pp 137-149

Wang B, Wang X, Chen Z (2013) A hybrid framework for reservoir characterization using fuzzy ranking and an artificial neural network. Comput Geosci 57:1-10

Watanabe N, Hirano N, Tsuchiya N (2008) Determination of aperture structure and fluid flow in a rock fracture by high-resolution numerical modeling on the basis of a flow-through experiment under confining pressure. Water Resour Res. doi:10.1029/ 2006WR005411

Witherspoon PA, Wang JSY, Iwai K, Gale JE (1980) Validity of cubic law for fluid flow in a deformable rock fracture. Water Resour Res 16:1016-1024

Wu PT (2013) Fracture aperture estimation using multi-axial induction tool. Filed by Schlumberger Technology Corporation, Sugar Land, TX (US), as Appl. No. 13/784,153

Zadeh LA (1965) Fuzzy sets. Inf Control 8:338-353

Zimmerman RW, Bodvarsson GS (1996) Hydraulic conductivity of rock fractures. Transp Porous Media 23:1-30

Zuperl U, Cus F (2016) End milling optimization using teachinglearning-based optimization algorithm with cutting force model. Proc Manuf Syst 11(2):57-62

\section{Publisher's Note}

Springer Nature remains neutral with regard to jurisdictional claims in published maps and institutional affiliations. 